climatology and hydrology, biogeography, physical and economic geography, etc. Each of these sections paid much attention to environmental problems and formulated their own specific approaches and spheres of scientific competence in a broad spectrum of these often complex and widely interdisciplinary problems.

The general (plenary) Symposium on 'Scientific Forecasting of Anthropogenic Transformation, Improvement, and Conservation, of the Environment' terminated the discussion of these problems at the Congress. At this Symposium, review reports of specialists and information by representatives of permanent IGU Commissions and Working Groups were presented and discussed. The scientific results of this Symposium were extremely diverse, but can be characterized briefly in the following way.

Systematization and generalization on a global scale of the results of long-term observations of the changes in natural environments occurring under the influence of human activity have revealed that, under the conditions of the scientific and technological revolution, the rates of these changes increase. This very often leads to irreversible phenomena producing crucial (often negative) effects on the economic activity and living conditions of people in separate countries, regions, and indeed practically the whole world.

During the last 20 to 30 years the concept of the availability of natural resources and the degree of their exploitation have changed sharply. Water has become one of the scarcest resources in many of the most developed regions of the world: on the average, the quality of water resources has deteriorated in the whole world. Moreover during the last 20 to 30 years, under the influence of the growth of technological development and the increase in the volume of production on one hand, and, on the other, of more and more extensive exploitation of natural resources-expansion of ploughed lands, extermination of forests and many biota, and numerous other 'developments'-an anthropogenic influence on global climate has begun to be manifest.

Forecasts show that the rates of these changes tend to increase as time goes an, and in some cases catastrophic consequences are possible-for instance, according to some estimations, most polar ice will melt by the year 2050, which would cause extensive changes in the thermal regime and concomitant effects throughout the world.

During the often animated discussions, scientists from different countries were unanimous in considering it necessary to organize international unified systems of studying the changes of the natural environment and its principal components. Regarding this, the undersigned presented a scheme for the establishment of scientific bases for monitoring which would consist of the three main 'blocks': bioecological (sanitary-hygienic), geosystems or geoecological (natural-economic), and biospheric. General approaches and principles of the strategy of the world monitoring network were also characterized in the report in which this scheme was outlined.

The Symposium made an important contribution to asserting the problems of the impact of society on the environment as a strategic trend in modern geographical studies. The necessity of intensifying the elaboration of the general theory of interaction between Man and environment was especially well emphasized by Gilbert F. White of the United States.

At the Symposium the participants were emphatic and unanimous in their conclusion that only under conditions of peaceful coexistence and reduction of armies and armaments is it possible to realize very expensive projects on the conservation of the environment, the introduction of closed technological cycles, the creation of a world system of observations, and general control over the evolution of the environment.

\author{
Innokentil Petrovich Gerasimov, Director \\ Institute of Geography of the USSR \\ Academy of Sciences \\ 29 Staromonetny pereulok \\ Moscow 109017 , \\ USSR.
}

\title{
Motorists Facing Their Responsibilities
}

The International Touring Alliance (AIT), with headquarters in Geneva, Switzerland, has taken upon itself the initiative of enabling motorists, car manufacturers, oil companies, planners, and environmentalists, to present their various cases at its Sixth Congress on Leisure and Touring to be held in Manila, Philippines, from 5 to 9 December 1977, on the theme of 'The Motorist and the Environment'.

Problems of motor traffic and its coexistence with Nature will thus be widely discussed for the first time under the auspices of the AIT, and with the cooperation of leading governmental and non-governmental international organizations. Experts from practically all parts of the world-from industrialized as well as developing countries-have been invited to evaluate the social and economic advances that have been ushered in by the age of the automobile, and to weigh them against the concomitant dangers menacing the quality of our environment and its healthgiving potential, while considering also the cultural values of tourism.

First of all the participants of the Congress will examine the ambiguous position of the motorist who, while incarnating the modern progress of our society towards independence and higher living-standards, is accused of jeopardizing the common patrimony and of enjoying his individual mobility to the detriment of future generations. Secondly the Congress will examine means of enabling countries that are in stages of industrial growth to avoid the problems that have been encountered elsewhere as a result of rapid increase in motor-car production, without depriving the people of those less-industrialized countries of the undeniable advantages of the motor-car as a treasured companion for work and pleasure.

Finally the participants will study the progress of motor technology with a view to reconciling the automobile with the ever-growing ecological requirements of an environmentally-awakened world, and thus to offer to future motorists the satisfaction of both mastering their vehicle and conserving Nature while enjoying it.

The authorities of the Philippines are giving their full support to the preparation of this event which is being organized by the national affiliate of the AIT, the Philippine Motor Association. The national airline, PAL, is preparing a special travel and excursion 'package' on very advantageous terms.

Vladimir M. Kabes, Secretary-General International Touring Alliance Quai Gustave-Ador 2

1207 Geneva

Switzerland. 